\title{
LA ALIMENTACIÓN DE LOS ANTIGUOS MAYAS \\ DE LA PENÍNSULA DE YUCATÁN: CONSIDERACIONES SOBRE LA IDENTIDAD Y LA CUISINE EN LA ÉPOCA PREHISPÁNICA
}

\author{
David Alejandro Herrera Flores \\ Christopher MARKus GÖTZ \\ Facultad de Ciencias Antropológicas \\ Universidad Autónoma de Yucatán
}

\begin{abstract}
RESUMEN: El presente estudio propone, mediante los resultados del análisis zooarqueológico de varias muestras de arqueofauna vertebrada recuperadas en sitios tierra adentro y costeros de la Península de Yucatán, determinar la dieta y la cuisine de los mayas prehispánicos de los periodos Clásico Tardío y Terminal. La meta principal radica en una propuesta para determinar el patrón culinario, entendiendo a éste como el resultado de las diferentes formas o elecciones en las que la comida es seleccionada, obtenida y preparada, del sitio de Isla Cerritos, en comparación al de otros asentamientos en tierra adentro y la costa, y en relación a su temporalidad y ambiente circundante. Las elecciones que resultan de este proceso, y que determinan la cuisine de un grupo, pueden llegar a constituir distintivos culturales que reflejan las preferencias que definen qué taxón e individuo de animal es cazado y cómo cada uno, o sus partes, son preparados para el consumo alimentario. Considerando, en seguimiento a estos argumentos, que los patrones culinarios pueden reflejar una "identidad cultural", relacionamos los resultados del estudio taxonómico y tafonómico con información etnográfica e histórica, en un intento de revelar patrones culinarios típicos de la región maya peninsular, destacando la posibilidad de continuidad, desde la época prehispánica hasta nuestros días, de prácticas culinarias como el Píib.
\end{abstract}

Palabras Clave: zooarqueología, alimentación, dieta, cuisine, identidad.

ABSTRACT: Through the results of zooarchaeological analysis of several samples of vertebrate archaeofauna recovered at inland and coastal sites of the Yucatan Peninsula, this study proposes to determine the diet and cuisine of the prehispanic Maya of the Late and Terminal Classic periods. The main goal resides in a proposal to determine the culinary pattern, understanding it as the result of the different forms in which food is selected, obtained and prepared, at the site of Isla Cerritos, compared to that of inland and coastal settlements, and in relation to its temporality and surrounding environment. The elections that result from this process, and determine the cuisine of a group, can constitute a distinctive cultural trait that reflects the preferences that define what taxon and individual animal is hunted and how each one, or parts thereof, are prepared for the food consumption. Considering, through these arguments, that culinary patterns may reflect a "cultural identity", we relate the results of a taxonomic and taphonomic study with ethnographic and historical information in an attempt to reveal culinary patterns typical for the peninsular Maya region, highlighting the possibility of continuity, from prehispanic times to our days, of culinary practices as the Píib.

KEYWORDS: zooarchaeology, food, diet, cuisine, identity.

RECEPCIÓN: 22 de julio de 2013.

ACEPTACIÓN: 13 de septiembre de 2013. 



\title{
LA ALIMENTACIÓN DE LOS ANTIGUOS MAYAS DE LA PENÍNSULA DE YUCATÁN: CONSIDERACIONES SOBRE LA IDENTIDAD Y LA CUISINE EN LA ÉPOCA PREHISPÁNICA
}

\author{
David Alejandro Herrera Flores \\ Christopher Markus Götz \\ Facultad de Ciencias Antropológicas \\ Universidad Autónoma de Yucatán
}

\begin{abstract}
Antecedentes teóricos: la alimentación es cultura y rasgo de identidad
\end{abstract}
El acto de la ingesta de alimentos se divide en distintos pasos, que consisten en seleccionar alimentos, prepararlos y finalmente ingerirlos, obedeciendo a factores geográficos, económicos, sociales, culturales y psicológicos (Peláez, 1997: 13). Por esta razón debe considerarse que la ingesta de alimentos no se limita a la actividad meramente biológica y nutricional, sino que incorpora imperantemente a elementos sociales, psicológicos, económicos, simbólicos y religiosos (Contreras, 2002: 10). El manto cultural de la alimentación apunta a relaciones entre poblaciones humanas o grupos sociales y su medio ambiente, a la construcción simbólica de las culturas, y a las relaciones y estructuras sociales de las sociedades (Messer, 2002: 27), convirtiendo a la actividad del "comer" en un fenómeno social y cultural (Contreras, 2002: 11; Peláez, 1997).

La elección de los alimentos, como paso inicial del acto de comer, está determinada por las condiciones del medio ambiente y unida a la satisfacción de las necesidades del cuerpo, pero recibe también en gran medida influencias del sistema social, económico e ideológico (Douglas, 2002: 171-2). Más allá de un código biológico, los individuos aprenden a aceptar o rechazar, gustar o no gustar, preferir o evitar, de acuerdo con gustos que les han sido transmitidos como parte de una cocina cultural (Messer, 2002; Rozin, 2002).

Conocer los modos de obtención de los alimentos, así como por quién y cómo se preparan, aporta una masa considerable de información sobre el funcionamiento de una sociedad (Contreras, 2002: 14); el análisis de los modos de ingesta consiste en una forma de comprender procesos sociales y culturales (Peláez, 1997: 14), porque, en definitiva, los comportamientos alimentarios son una parte integrada en la totalidad cultural. Un cierto número de "indicadores" gustativos pueden afirmar una identidad alimentaria, delimitando la pertenencia culinaria a un territorio o grupo determinado. En cualquier caso, la función que pueden jugar los alimentos en la identidad individual y grupal puede ser muy importante (Contreras, 2002: 13; Messer, 2002: 48). 
Las identidades, a su vez, deben considerarse como la suma de procesos ideológicos constitutivos de la realidad social, que buscan organizar en un universo coherente el conjunto de relaciones reales e imaginarias que los humanos han establecido entre sí y con el mundo material, y que resultan necesarias para la reproducción y la trasformación social (Hernando, 2002: 50 y Pérez, 1992: 65).

La reconstrucción, reelaboración y reconstitución de las identidades implica por lo tanto procesos de adscripción y exclusión, mediante los cuales los agentes sociales crean, seleccionan, desechan o afirman marcas o rasgos de identificación (entre los cuales pueden incluirse los alimentos), que son reelaborados simbólicamente y que les permiten aglutinarse como una unidad o un grupo. Es así que la creación de una identidad dada se promueve en la medida en que un grupo social se considera con derechos para identificarse y actuar sobre un universo de elementos culturales que se conciben como propios, permitiéndole al grupo caracterizarse como diferente a otros (Pérez, 1992: 65).

En este sentido, la identidad es una construcción y un patrón sociocultural que a su vez es el resultado de un sinnúmero de procesos identificatorios y diferenciatorios, en los que básicamente se delimitan dos territorios: lo propio y lo ajeno (Tappan, 1992: 85). De esta manera, el término identidad tiene dos significados: uno es el concepto de semejanza, es decir, lo que hace posible una relación entre dos o más elementos; y el segundo es un concepto de distinción, ya que es a partir de que existe una posibilidad de diferencia que algo puede ser semejante (Hernando, 2002; Tappan, 1992; Vigliani, 2006).

En las sociedades, el acto de comer se concibe esencialmente como una actividad social, en donde las maneras como son preparados y servidos los alimentos, así como las restricciones respecto a algunos de ellos, expresan los modos mediante los cuales los individuos de diferentes sociedades proyectan sus identidades (Contreras, 2002: 14), básicamente "probando" su identidad comiendo los alimentos prescritos (Shack, 2002: 114).

Dado el significado simbólico de los alimentos, existe la posibilidad de poder identificar a las personas según lo que comen, del mismo modo que las mismas personas se identifican o "se construyen" mediante la comida, a través de determinados usos y preferencias alimentarias. Mediante un determinado comportamiento alimentario, un individuo puede expresar su voluntad de integración en un determinado grupo social (Contreras, 2002: 19; Counihan, 1999: 19), estableciéndose entonces un fuerte lazo entre los hábitos alimentarios y los aspectos de la identidad (Gates, 2006: 1).

Los restos de la comida: la zooarqueología y la identidad

Un camino para estudiar algunos aspectos de la alimentación en la época prehispánica pasa a través de las reminiscencias materiales de los alimentos. La zoo- 
arqueología, disciplina arqueológica dedicada al análisis de los restos esqueléticos de fauna hallados en yacimientos arqueológicos, abre la posibilidad de acercarse al estudio de los modos de alimentación cárnica del pasado mediante el análisis de los desperdicios de la comida (restos óseos) de los humanos pretéritos, así como de las marcas de procesamiento contenidas en éstos (Boscato, 2001; Reitz y Wing, 2008). Cabe mencionar que los restos arqueofaunísticos constituyen los residuos solamente de una parte del repertorio alimentario de un grupo humano, el cual pudo incluir además una gran variedad de recursos botánicos, de insectos e invertebrados, mismos que podrían referirse de manera equivalente como parte del esquema cultural de relación entre alimentación e identidad.

La relación entre el ser humano y el medio ambiente específico en el que vive se manifiesta mediante el aprovechamiento y la explotación de los recursos. El nivel de aprovechamiento depende altamente del repertorio tecnológico usado para obtener los recursos, pero también de la conceptualización cultural hacia la naturaleza, ya que ésta introduce conjuntos de reglas sobre el uso y la apropiación de la naturaleza, que darán la pauta para la adquisición y definición de patrones culturales que constituirán parte de la cultura de una comunidad, así como de la identidad de los mismos (Ellen, 2001: 124). Conceptualmente, se considera que la relación humano-naturaleza puede ser entendida como una serie de "estrategias de subsistencia”, las cuales son el producto de interacciones dinámicas entre la gente y el entorno ambiental, y a través de las cuales el ser humano obtiene una variedad de nutrientes necesarios para sus requerimientos biológicos básicos (Reitz y Wing, 2008).

Como subproducto analítico de las estrategias de subsistencia, podemos concebir tres términos relacionados al consumo alimentario, que comprenden la pauta para el entendimiento de los patrones de aprovechamiento y los modos de preparación, importantes en el estudio de la identidad (Reitz y Wing, 2008). Estos términos consisten en el menú, mismo que debe entenderse como la colección básica de alimentos disponibles en una situación ambiental dada, que se pueden aprovechar y específicamente comer; la dieta, que corresponde a los materiales que son efectivamente seleccionados del entorno y preparados para el consumo, y por último, la cuisine (o cocina), que consiste en el resultado de las diferentes formas en las que dichos materiales son seleccionados, preparados, distribuidos, servidos y consumidos. Son en gran medida estas últimas elecciones las que constituyen distintivos culturales, ya que definen las combinaciones de los alimentos y las maneras de prepararlos, los estilos de cocina, los roles sociales del cuándo, dónde y por quiénes son preparados y comidos, así como las circunstancias bajo las cuales son consumidos.

Los estudios zooarqueológicos que han tratado el tema de la identidad para los grupos sociales (por ejemplo Emery, 2002; Gates, 2006; Götz, 2010; Wing, 1981) se han basado en el análisis de los patrones de aprovechamiento, determinando la preferencia hacia el consumo de cierto(s) animal(es) vertebrado(s), y 
considerando la diferencia en el uso de los animales como parte de un patrón de subsistencia asociado con diferentes aspectos culturales (Wing, 1981: 21). De tal manera, puede considerarse que a través del análisis taxonómico y tafonómico de los huesos arqueológicos de animales se pueden reconocer algunos de los rasgos o patrones que pudieron llegar a constituirse como parte de la identidad de los habitantes de una región y de un tiempo dado en la historia. La zooarqueología nos permite utilizar e interpretar parte de la información revelada por los restos faunísticos como un marcador de identidad.

La preparación de los alimentos involucra, entre otros, los procesos de la carnicería, la mezcla de ingredientes, la cocción y la presentación de los platillos, buscando en un caso óptimo reminiscencias de estos procesos en el registro arqueológico. Sin embargo, una de las principales limitantes para la reconstrucción de dichos procesos consiste en la conservación diferencial del material arqueológico, sobre todo de las materias orgánicas que servían de alimento en el pasado, ya que una gran cantidad de agentes tafonómicos —uno de los cuales es la propia ingesta de los alimentos- influyen de manera sustancial en el nivel de inferencia al cual podemos llegar; las actividades humanas (como el carnicéo, la fractura de los huesos, la cocción, etc.) y los factores naturales externos (composición y pH del suelo, el roído de animales, etc.) o de la propia estructura del hueso (densidad ósea, tamaño, estructura química, etc.) repercuten en la composición de una muestra arqueofaunística, por lo que es importante considerar estos factores al momento de realizar nuestras interpretaciones. La frecuencia de partes esqueléticas en una muestra debe entenderse como resultado de una serie de procesos culturales y naturales que llevaron a la conformación de dicho contexto (Lyman, 2001 y Nicholson, 1998).

Las primeras actividades para la preparación de los alimentos, que reflejarían la cuisine, son la carnicería y la cocción, considerando que en primera instancia se realiza la selección y caza del animal como parte de este mismo proceso. Partes de animales que han pasado por estas actividades pueden ser reconocidas potencialmente en una muestra zooarqueológica, a través del análisis de marcas de corte, fractura por impacto y huellas de calor directo (fuego), marcas que corresponden a actividades como el despellejamiento y descarnamiento, la desarticulación y rotura de huesos, el hervido y rostizado, y que son consideradas como parte importante en la interpretación del presente estudio. Sin embargo, la mezcla de ingredientes y la presentación de los platillos no son fáciles de reconstruir, ya que los factores que involucran difícilmente podrán ser observados a través de los restos óseos de los animales debido a que no existe evidencia que nos permita decir qué ingredientes se necesitaban o cómo debieron integrarse para la elaboración de ciertos platillos. Aunado a este punto hay que considerar que los desechos de varios y posiblemente diferentes platillos, que pudieran haber reflejado la cuisine de un grupo en tiempos precolombinos, aparecen comúnmente mezclados en las acumulaciones de restos faunísticos, en los basureros primarios o secundarios (Götz, 2005). 
La reconstrucción de los modos de preparación de los alimentos se basa en el análisis de las marcas antrópicas en la superficie de los restos óseos, a través de la determinación de patrones de ciertas marcas en determinadas especies o partes anatómicas, que ayudan a establecer diferencias o similitudes en el modo de procesar cada uno de los tipos de animales usados en la dieta de las poblaciones. El análisis de los modos de procesamiento reflejaría el uso de una o varias formas o técnicas de preparación, al igual que la preferencia en el empleo de alguna de éstas para cocinar los alimentos (por ejemplo, la mayor presencia en una muestra de marcas de hervido en relación a las marcas de fuego directo que podrían estar relacionadas con actividades como el asado).

Para el desarrollo de este trabajo se establecieron dos niveles de interpretación para la identificación de posibles rasgos de identidad en sociedades antiguas, ambos basados en la reconstrucción de la cuisine prehispánica: por un lado, la reconstrucción de la dieta (que refiere básicamente a los perfiles taxonómicos en una muestra), tomando en consideración la preferencia en el consumo de ciertos animales, y, por otro, la identificación de marcas antrópicas relacionadas con la elaboración de los alimentos, ya que estos últimos pudieran permitir trazar diferencias entre grupos que quizá estén consumiendo las mismas especies de animales (p. ej. una predominancia en el proceso de asado sobre el de hervido como medio de cocción de los alimentos).

El primer nivel de inferencia, la dieta, se basa en la comparación e identificación de similitudes o diferencias en cuanto a los animales cazados para el aprovechamiento alimentario en un asentamiento, permitiéndonos establecer también posibles preferencias en la explotación de ciertas especies sobre otras. Por otra parte, las interpretaciones basadas en los modos de procesamiento de los animales (o de preparación de los alimentos) nos permiten apreciar el tratamiento que los antiguos habitantes de los sitios les realizaron a los animales, o a partes de estos, antes de consumirlos.

\section{Materiales y métodos: los estudios de caso costeros y de tierra adentro}

Las inferencias del presente artículo se basan en dos estudios de caso, uno de sitios tierra adentro, el otro de un sitio costero en Yucatán. Dentro del marco de esta investigación se consideró que el análisis de una sola muestra arqueofaunística no puede ser capaz de responder a las preguntas planteadas, ya que, al tratar el tema de la identidad, se requiere de un estudio que involucre diferentes muestras y/o sitios, debido a que el significado de identidad nace cuando se establece una relación entre dos o más grupos permitiendo construir un vínculo de semejanza o diferencia.

El primer estudio se refiere al del sitio arqueológico costero de Isla Cerritos, Yucatán. Este yacimiento precolombino se encuentra sobre una pequeña ínsula de unos 200 metros de diámetro, que se localiza aproximadamente a 500 metros de la costa norte de Yucatán, a unos cinco kilómetros del puerto de San Felipe 
en dirección oeste (Andrews et al., 1988: 196). En Isla Cerritos se realizaron, en tiempos recientes, varias campañas de excavación (Cobos et al., 2007 y 2010) que pretendieron investigar el estilo de vida de los habitantes de uno de los principales sitios costeros de norte de la Península de Yucatán, considerando que el sitio fue el más importante puerto de intercambio de Chichén Itzá en la costa norte yucateca durante el periodo Clásico Terminal (800 d.C.-1100 d.C.), un hecho que presuntamente permitió el desarrollo de nuevas ideas y elementos culturales panmesoamericanos en el sitio (Kowalski y Kirstian-Graham, 2007). Estudios anteriores han sugerido que Isla Cerritos era el puerto principal de Chichén Itzá, ya que las asociaciones de cerámica (Andrews et al., 1984 y 1986; Cobos et al., 2007 y 2010) y artefactos líticos (Braswell, 1997) indican relaciones fuertes y sostenidas con el sitio de Chichén Itzá; además, el rango de objetos de comercio recuperados en Isla Cerritos es en gran medida un reflejo de los encontrados en este asentamiento tierra adentro.

El asentamiento de Isla Cerritos consta, en total, de las ruinas de 29 estructuras, que incluyen arquitectura monumental y zonas residenciales, así como los vestigios parcialmente sumergidos de alineamientos de piedras y los restos de cimientos de un muro de piedra localizado dentro del mar en la periferia inmediata de la ínsula y que sigue el contorno de la orilla sur de la misma. Los elementos constructivos más evidentes en el sitio son los relacionados con las facilidades portuarias, mismos que consisten en alineamientos de piedras y rellenos constructivos que han sido interpretados como los vestigios de terrazas, muelles y embarcaderos (Andrews et al., 1988; Andrews y Gallareta, 1986; Gallareta y Andrews, 1988; Gallareta et al., 1989).

El estudio zooarqueológico realizado en Isla Cerritos fue efectuado por Herrera Flores (2011) y tuvo como meta revelar las preferencias alimentarias de los habitantes del sitio. La investigación propuso analizar cómo influyeron tendencias alimentarias del sitio de Chichén Itzá en el modo de alimentación de los pobladores de Isla Cerritos, para aclarar si existe un patrón de aprovechamiento particular (relacionado a estas nuevas ideas y elementos culturales) en el sitio que lo distinga claramente de las estrategias de subsistencia "generalizadas" que han sido establecidas para otros lugares costeros de las Tierras Bajas del norte (Götz, 2007a y 2008a; Jiménez Cano, 2009; Márquez Morfín, 1991). La hipótesis de trabajo postuló que pudieron haberse usado, en Isla Cerritos, estrategias de subsistencia y técnicas de procesamiento con una fuerte influencia desde la principal ciudad de las Tierras Bajas mayas durante el periodo Clásico Terminal, Chichén Itzá. Un elemento muy importante a considerar, en relación a la presencia de nuevas ideas culturales que pudieran haber estado ligadas a un patrón particular de aprovechamiento de la fauna, es que Isla Cerritos y Chichén Itzá se ubican en dos ambientes ecológicos completamente diferentes; por un lado, la primera se encuentra en un ambiente costero, en tanto que la segunda está asentada en las planicies centrales del norte de la península, en un ambiente tierra adentro, lo que implica el acceso a diferentes especies de animales únicas de cada ambiente. 
La muestra de Isla Cerritos recurrida para este trabajo contó con un total de 2354 especímenes esqueléticos (fragmentos y elementos completos), excavados en cinco estructuras precolombinas $(3,5,8,12$ y 23) (figura 1). La mayor parte de los restos faunísticos fue hallada en rellenos constructivos y en superficies antiguas, fechados para el periodo Clásico Terminal. Se considera que los contextos culturales de fauna, en gran parte, deben ser entendidos como basureros primarios o secundarios, en términos generales, como reminiscencia de actividades culturales relacionadas al aprovechamiento de la fauna marítima de la costa yucateca, lo cual se puede apreciar en la gran cantidad de restos de peces, tortugas marinas y cangrejos que fueron recuperados (Götz, 2012; Herrera Flores, 2011; Jiménez Cano, 2009). Los antiguos pobladores del asentamiento explotaban con menor frecuencia fauna de zonas del interior de la franja costera, como el venado cola blanca (Odocoileus virginianus), la iguana rayada (Ctenosaura similis) y tortugas de tierra. En cuanto a las técnicas empleadas en el procesamiento de los animales, destacan la desarticulación de animales como la tortuga de mar y el venado, y el empleo del hervido como método de cocción (Cárdenas Cervantes, 2012; Cobos et al., 2010; Götz, 2012).

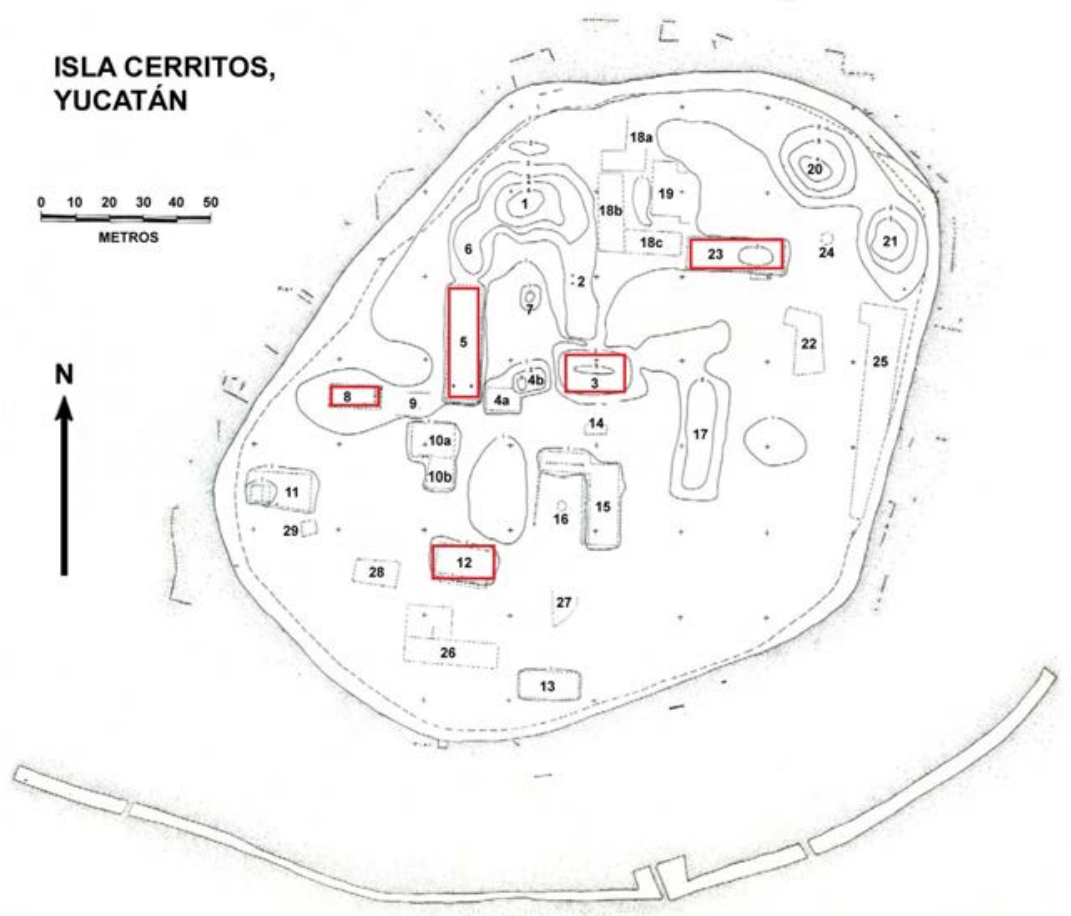

FigurA 1. El sitio arqueológico de Isla Cerritos, Yucatán, México (tomada de Cobos et al., 2007, y modificada por Herrera Flores). 
La dieta y los patrones de procesamiento observados en el sitio de Isla Cerritos se compararon con los datos de dos muestras arqueofaunísticas de sitios localizados en el norte de las Tierras Bajas mayas (figura 2). En primer lugar, se utilizó, para tal fin, una muestra del sitio arqueológico de Chichén Itzá (correspondiente a un contexto faunístico fechado para el período Clásico Terminal, procedente de un basurero localizado en el Grupo de la Serie Inicial), debido a la estrecha relación comercial que mantuvo con Isla Cerritos. El contexto se encontró al oeste afuera de la plataforma del grupo arquitectónico, al lado de la estructura 5C6 o "Galería de los monos", y corresponde a la más grande acumulación de basura del grupo, ya que muestra posiblemente los desechos domésticos de la mayoría de los edificios del mismo.

En este contexto se recuperaron 4002 huesos o fragmentos óseos de origen animal, mezclados con tiestos, lítica y algunos huesos humanos, que fueron analizados por Götz (2007b, 2008b). En lo que respecta a la muestra faunística, la mayor cantidad de huesos de este basurero se atribuye a los mamíferos (94\%), seguida por reptiles $(4 \%)$, aves $(2 \%)$ y peces óseos (actinopterigios) $(0,03 \%)$. La mayoría de los huesos de mamíferos pertenece a venados cola blanca (Odocoileus virginianus) (60\%). Las especies de reptiles identificadas fueron iguanas rayadas (Ctenosaura similis) (95\% de la muestra total de reptiles), y tortugas de agua dulce y de tierra. De las aves se encontraron únicamente pocos restos óseos de hocofaisán (Crax rubra) y de pavo de monte (Meleagris ocellata) (Götz, 2007b: 54, 56).

Posteriormente se compararon los patrones observados en Isla Cerritos con datos arqueofaunísticos de una muestra del sitio prehispánico de Xcambó, el cual consiste en un asentamiento costero ubicado en una zona ecológica, geográfica y geológica semejante a la de Isla Cerritos (Götz y Sierra Sosa, 2011; Götz, 2012), y presenta un periodo de ocupación (Clásico Temprano-Clásico Tardío) (Jiménez Álvarez, 2002) que permite estudiar las estrategias de subsistencia en un sitio costero durante un periodo anterior al Clásico Terminal. Los materiales arqueofaunísticos formaron parte de rellenos constructivos o se hallaban encima de antiguas superficies de uso, tal como se ha descrito para Isla Cerritos, por lo que se aprecia una ausencia de basureros formales (Götz y Sierra Sosa, 2011: 124).

La muestra arqueofaunística de Xcambó consta de 1539 especímenes, fue analizada por Götz y Sierra Sosa (2011), y procede de la porción oeste del sitio (plaza oeste y estructuras NE2, NE14, NE19, NO1, NO2, NO4 y NO9). Entre los fragmentos esqueléticos se encontraron crustáceos $(7,7 \%)$, peces (actinopterigios y condrictios) $(38,8 \%)$, reptiles $(34 \%)$, aves $(3,7 \%)$ y mamíferos $(15,8 \%)$. Entre la fauna íctica se destacan diversos géneros de tiburones y peces como el bagre (Ariopsis felis), el mero (Epinephelus sp.), la gurrubata (Micropogonias sp.) y el robalo (Centropomus sp.). Los reptiles más representados son las tortugas de mar (65,5\% de la muestra total de reptiles), seguidas de iguanas y tortugas de tierra y agua dulce. Respecto a los mamíferos, el más frecuente es el venado cola blanca (Odocoileus virginianus) (Götz y Sierra Sosa, 2011). 


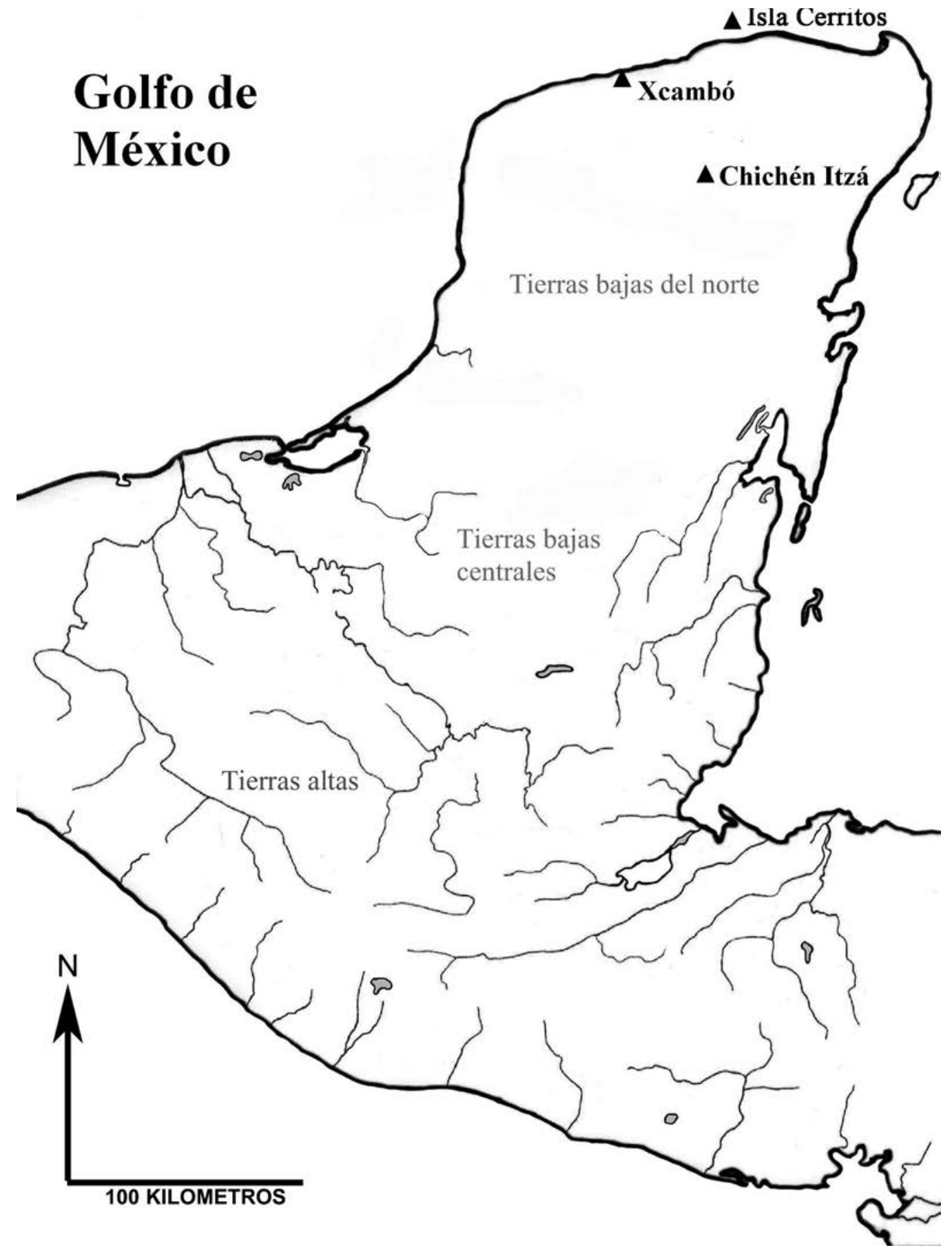

Figura 2. Mapa de la Península de Yucatán indicando la ubicación de los sitios arqueológicos de donde provienen las muestras zooarqueológicas comparadas (tomado de Götz, 2008a, y modificado por Herrera Flores). 


\section{Resultados}

Como resultado del cotejo entre las muestras podemos observar una marcada diferencia entre los perfiles taxonómicos de las especies aprovechadas como recurso alimentario entre los sitios costeros y el de tierra adentro (tabla 1).

\begin{tabular}{|c|c|c|c|c|c|c|c|c|}
\hline Taxón & $\begin{array}{c}\text { Isla Cerritos } \\
(\mathrm{N}=2354)\end{array}$ & Xcambó (N=1539) & \multicolumn{6}{|c|}{ Chichén Itzá (N=4002) } \\
\hline \multirow{19}{*}{ 芯 } & \multirow{19}{*}{ Actinopterigios } & & NISP* & $\%$ NISP $^{* * *}$ & NISP* & 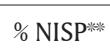 & NISP* & \% NISP** \\
\hline & & Carangidae & & & 1 & 0,06 & & \\
\hline & & $\begin{array}{l}\text { Centropomidae } \\
\text { o Sciaenidae }\end{array}$ & 1 & 0,04 & & & & \\
\hline & & Perciforme & 4 & 0,17 & & & & \\
\hline & & Pomacanthidae & 1 & 0,04 & & & & \\
\hline & & $\begin{array}{l}\text { Archosargus spp } \\
\text { o Calamus spp }\end{array}$ & & & 1 & 0,06 & & \\
\hline & & Ariopsis felis & 106 & 4,5 & 68 & 4,36 & & \\
\hline & & Calamus spp & 1 & 0,04 & & & & \\
\hline & & Calamus leucosteus & & & 4 & 0,26 & & \\
\hline & & Caranx spp & 3 & 0,13 & & & & \\
\hline & & Caranx latus & 1 & 0,04 & & & & \\
\hline & & $\begin{array}{l}\text { Centropomus spp } \\
\text { o Epinephelus spp }\end{array}$ & 3 & 0,13 & & & & \\
\hline & & Centropomus spp & 2 & 0,08 & 174 & 11,16 & & \\
\hline & & $\begin{array}{l}\text { Centropomus } \\
\text { undecimalis }\end{array}$ & 35 & 1,49 & & & & \\
\hline & & Epinephelus spp & 3 & 0,13 & 14 & 0,9 & & \\
\hline & & Epinephelus morio & 55 & 2,34 & 1 & 0,06 & & \\
\hline & & Haemulon plumierii & 1 & 0,04 & & & & \\
\hline & & Lutjanus spp & 1 & 0,04 & 7 & 0,45 & & \\
\hline & & $\begin{array}{l}\text { Lutjanus } \\
\text { cyanopterus }\end{array}$ & 11 & 0,47 & & & & \\
\hline
\end{tabular}

Tabla 1. Perfiles taxonómicos de las tres muestras zooarqueológicas comparadas (Isla Cerritos, Xcambó y Chichén Itzá).

*Conteo de especímenes o número de especímenes identificados por taxón (NISP por sus siglas en inglés).

***Cantidad porcentual (porcentaje) del NISP dentro de la muestra total. 


\begin{tabular}{|c|c|c|c|c|c|c|c|c|}
\hline Taxón & $\begin{array}{c}\text { Isla Cerritos } \\
(\mathrm{N}=2354)\end{array}$ & Xcambó (N=1539) & \multicolumn{6}{|c|}{ Chichén Itzá (N=4002) } \\
\hline \multirow{29}{*}{ 总 } & \multirow{10}{*}{ Actinopterigios } & & NISP* & $\% \mathrm{NISP}^{* *}$ & NISP* & \% NISP ${ }^{* *}$ & NISP* & $\%$ NISP \\
\hline & & Megalops sp & 1 & 0,04 & & & & \\
\hline & & Megalops atlanticus & 5 & 0,21 & & & & \\
\hline & & Micropogonias spp & & & 32 & 2,05 & & \\
\hline & & $\begin{array}{l}\text { Micropogonias } \\
\text { undulatus }\end{array}$ & 30 & 1,27 & & & & \\
\hline & & Opsanus spp & & & 4 & 0,26 & & \\
\hline & & Opsanus beta & 44 & 1,87 & & & & \\
\hline & & $\begin{array}{l}\text { Cynoscion } \\
\text { nebulosus }\end{array}$ & 4 & 0,17 & & & & \\
\hline & & Sphoeroides spp & 1 & 0,04 & & & & \\
\hline & & $\begin{array}{l}\text { Actinopterigio } \\
\text { no identificado }\end{array}$ & 132 & 5,61 & 40 & 2,57 & 1 & 0,02 \\
\hline & & Rajiformes & & & 8 & 0,51 & & \\
\hline & & Aetobatus spp & & & 5 & 0,32 & & \\
\hline & Rayas & Aetobatus narinari & 1 & 0,04 & & & & \\
\hline & & Dasyatis spp & 6 & 0,25 & & & & \\
\hline & & Dasyatis americana & 2 & 0,08 & 1 & 0,06 & & \\
\hline & & Carcharhinus spp & 90 & 3,82 & 188 & 12,06 & & \\
\hline & & $\begin{array}{l}\text { Carcharhinus } \\
\text { acronotus }\end{array}$ & 6 & 0,25 & & & & \\
\hline & & $\begin{array}{l}\text { Carcharhinus } \\
\text { altimus }\end{array}$ & 2 & 0,08 & & & & \\
\hline & & $\begin{array}{l}\text { Carcharhinus } \\
\text { brevipinna }\end{array}$ & 1 & 0,04 & & & & \\
\hline & & $\begin{array}{l}\text { Carcharhinus } \\
\text { limbatus }\end{array}$ & 1 & 0,04 & & & & \\
\hline & & $\begin{array}{l}\text { Carcharhinus } \\
\text { obscurus }\end{array}$ & 8 & 0,34 & & & & \\
\hline & y pez sierra & Galeocerdo cuvier & 7 & 0,3 & 12 & 0,77 & & \\
\hline & & $\begin{array}{l}\text { Ginglymostoma } \\
\text { cirratum }\end{array}$ & 4 & 0,17 & 12 & 0,77 & & \\
\hline & & Mustelus norrisi & 1 & 0,04 & & & & \\
\hline & & Pristis pectinata & 14 & 0,59 & & & & \\
\hline & & $\begin{array}{l}\text { Rhizoprionodon } \\
\text { terraenovae }\end{array}$ & 48 & 2,04 & 22 & 1,41 & & \\
\hline & & Sphyrna spp & 3 & 0,13 & 1 & 0,06 & & \\
\hline & & Sphyrna tiburo & & & 2 & 0,13 & & \\
\hline & & $\begin{array}{l}\text { Condrictio } \\
\text { no identificado }\end{array}$ & 12 & 0,51 & & & & \\
\hline
\end{tabular}




\begin{tabular}{|c|c|c|c|c|c|c|c|c|}
\hline Taxón & $\begin{array}{l}\text { Isla Cerritos } \\
(\mathrm{N}=2354)\end{array}$ & Xcambó (N=1539) & \multicolumn{6}{|c|}{ Chichén Itzá (N=4002) } \\
\hline \multirow{24}{*}{$\stackrel{n}{\gtrless}$} & \multirow{10}{*}{ Aves de mar } & & NISP* & $\% \mathrm{NISP}^{* *}$ & NISP* & $\%$ NISP** & NISP* & $\% \mathrm{NISP}^{* * *}$ \\
\hline & & Ardea herodias & 3 & 0,13 & 1 & 0,06 & & \\
\hline & & Egretta spp & & & 5 & 0,32 & & \\
\hline & & Egretta thula & 28 & 1,19 & & & & \\
\hline & & Fregata magnificens & 1 & 0,04 & & & & \\
\hline & & Pelecanus spp & & & 6 & 0,38 & & \\
\hline & & $\begin{array}{l}\text { Pelecanus } \\
\text { occidentalis }\end{array}$ & 1 & 0,04 & & & & \\
\hline & & $\begin{array}{l}\text { Phalacrocorax } \\
\text { auritus }\end{array}$ & 18 & 0,76 & & & & \\
\hline & & $\begin{array}{l}\text { Phoenicopterus } \\
\text { ruber }\end{array}$ & 4 & 0,17 & & & & \\
\hline & & Sula spp & & & 1 & 0,06 & & \\
\hline & & Cracidae & & & 1 & 0,06 & & \\
\hline & & Galliformes & & & 2 & 0,13 & 18 & 0,45 \\
\hline & Pavos & Meleagris spp & & & 13 & 0,83 & 25 & 0,62 \\
\hline & y especies afines & Meleagris ocellata & & & 4 & 0,26 & 15 & 0,37 \\
\hline & & $\begin{array}{l}\text { Puffinus spp } \\
\text { o Gallinula chloropus }\end{array}$ & & & 1 & 0,06 & & \\
\hline & Buitres & Coragyps atratus & 27 & 1,15 & & & & \\
\hline & Aves & Anatidae & & & 1 & 0,06 & & \\
\hline & medianas & Crax rubra & & & & & 1 & 0,02 \\
\hline & & $\begin{array}{l}\text { Aratinga spp } \\
\text { o Amazona spp }\end{array}$ & & & 1 & 0,06 & & \\
\hline & & $\begin{array}{l}\text { Bartramia } \\
\text { longicauda }\end{array}$ & & & 1 & 0,06 & & \\
\hline & $\begin{array}{c}\text { Aves } \\
\text { pequeñas }\end{array}$ & $\begin{array}{l}\text { Cyanocorax } \\
\text { yucatanicus }\end{array}$ & 1 & 0,04 & & & & \\
\hline & & Columbidae & 1 & 0,04 & & & & \\
\hline & & Columba livia & 2 & 0,08 & & & & \\
\hline & & Ave no identificada & 58 & 2,46 & 20 & 1,28 & 23 & 0,57 \\
\hline & & Cheloniidae & 684 & 29,06 & 241 & 15,46 & & \\
\hline 岃 & & Caretta caretta & 122 & 5,18 & 49 & 3,14 & & \\
\hline E & Tortugas de mar & Chelonia mydas & 47 & 2 & 31 & 1,99 & & \\
\hline $\bar{\alpha}$ & & $\begin{array}{l}\text { Eretmochelys } \\
\text { imbricata }\end{array}$ & 92 & 3,91 & 16 & 1,03 & & \\
\hline
\end{tabular}




\begin{tabular}{|c|c|c|c|c|c|c|c|c|}
\hline Taxón & $\begin{array}{c}\text { Isla Cerritos } \\
(\mathrm{N}=2354)\end{array}$ & Xcambó (N=1539) & & Chi & chén It & zá $(\mathrm{N}=40$ & $02)$ & \\
\hline \multirow{15}{*}{ 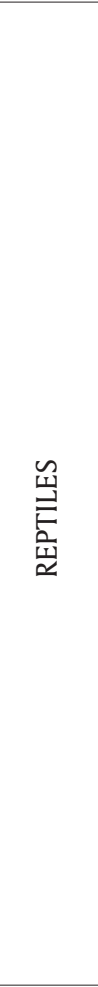 } & \multirow{13}{*}{ Tortugas de mar } & & NISP* & $\% \mathrm{NISP}^{* *}$ & NISP* & $\% \mathrm{NISP}^{* * *}$ & NISP* & $\%$ NISP $^{* * *}$ \\
\hline & & Emydidae & 1 & 0,04 & & & & \\
\hline & & $\begin{array}{l}\text { Kinosternidae o } \\
\text { Emydidae }\end{array}$ & 2 & 0,08 & & & & \\
\hline & & Kinosternon spp & & & 62 & 3,98 & 3 & 0,07 \\
\hline & & Kinosternon acutum & 1 & 0,04 & & & & \\
\hline & & $\begin{array}{l}\text { Kinosternon } \\
\text { leucostomum }\end{array}$ & 6 & 0,25 & & & & \\
\hline & & $\begin{array}{l}\text { Terrapene } \\
\text { o Kinosternon }\end{array}$ & & & 2 & 0,13 & & \\
\hline & & Terrapene spp & & & 7 & 0,45 & & \\
\hline & & Terrapene carolina & 3 & 0,13 & & & & \\
\hline & & Trachemys spp & & & 6 & 0,38 & 2 & 0,05 \\
\hline & & Trachemys scripta & 10 & 0,42 & & & & \\
\hline & & Dermatemys mawii & 6 & 0,25 & 1 & 0,06 & & \\
\hline & & $\begin{array}{l}\text { Tortuga } \\
\text { no identificada }\end{array}$ & 3 & 0,13 & 6 & 0,38 & 4 & 0,1 \\
\hline & Cocodrilos & $\begin{array}{l}\text { Crocodylus } \\
\text { moreletii }\end{array}$ & 3 & 0,13 & 7 & 0,45 & & \\
\hline & Iguanas & Ctenosaura similis & 103 & 4,38 & 96 & 6,16 & 156 & 3,9 \\
\hline \multirow{12}{*}{ 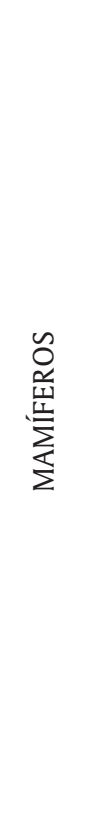 } & \multirow{12}{*}{ Artiodáctilos } & Cervidae & 7 & 0,3 & & & 323 & 8,07 \\
\hline & & $\begin{array}{l}\text { Cervidae } \\
\text { o Tayassuidae }\end{array}$ & & & & & 6 & 0,15 \\
\hline & & Tayassuidae & & & & & 5 & 0,12 \\
\hline & & Pecari tajacu & & & 9 & 0,58 & 27 & 0,67 \\
\hline & & Tayassu pecari & & & & & 4 & 0,1 \\
\hline & & Mazama spp & & & 4 & 0,26 & 90 & 2,25 \\
\hline & & Mazama pandora & & & 1 & 0,06 & & \\
\hline & & $\begin{array}{l}\text { Odocoileus } \\
\text { virginianus }\end{array}$ & 118 & 5,01 & 106 & 6,8 & 2250 & 56,24 \\
\hline & & Bos taurus & 3 & 0,13 & 2 & 0,13 & & \\
\hline & & $\begin{array}{l}\text { Bos taurus } \\
\text { o Equus caballus }\end{array}$ & & & 2 & 0,13 & & \\
\hline & & $\begin{array}{l}\text { Bovidae, Equidae } \\
\text { o Tapiridae }\end{array}$ & & & 3 & 0,19 & & \\
\hline & & $\begin{array}{l}\text { Artiodáctilo } \\
\text { no identificado }\end{array}$ & & & & & 3 & 0,07 \\
\hline
\end{tabular}




\begin{tabular}{|c|c|c|c|c|c|c|c|c|}
\hline Taxón & Isla Cerritos & Xcambó (N=1539) & \multicolumn{6}{|c|}{ Chichén Itzá (N=4002) } \\
\hline \multirow{22}{*}{ 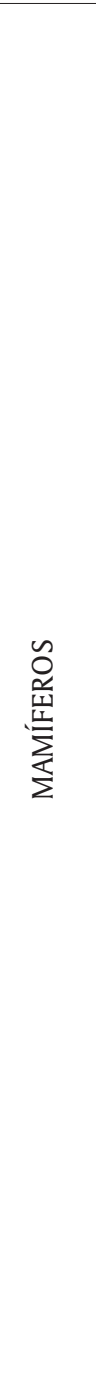 } & \multirow{3}{*}{ Perisodáctilos } & & NISP* & $\% \mathrm{NISP}^{* * *}$ & NISP* & $\% \mathrm{NISP}^{* * *}$ & NISP* & $\%$ NISP ${ }^{* *}$ \\
\hline & & Equus caballus & & & 7 & 0,45 & & \\
\hline & & Tapirus bairdii & 1 & 0,04 & 13 & 0,83 & & \\
\hline & & Canidae o Ursidae & & & 1 & 0,06 & & \\
\hline & & $\begin{array}{l}\text { Canis lupus } \\
\text { familiaris }\end{array}$ & 5 & 0,21 & 17 & 1,09 & 49 & 1,22 \\
\hline & Carnívoros & Procyon lotor & 1 & 0,04 & 3 & 0,19 & & \\
\hline & & $\begin{array}{l}\text { Urocyon } \\
\text { cinereoargenteus }\end{array}$ & & & 9 & 0,58 & & \\
\hline & & Nasua narica & & & & & 1 & 0,02 \\
\hline & & $\begin{array}{l}\text { Dasyproctidae } \\
\text { o Cuniculidae }\end{array}$ & 1 & 0,04 & & & & \\
\hline & Roedores & Cuniculus paca & & & 4 & 0,26 & 1 & 0,02 \\
\hline & & Dasyprocta punctata & 1 & 0,04 & & & & \\
\hline & & Sylvilagus spp & & & 4 & 0,26 & 17 & 0,42 \\
\hline & Armadillos & $\begin{array}{l}\text { Dasypus } \\
\text { novemcinctus }\end{array}$ & & & 1 & 0,06 & 1 & 0,02 \\
\hline & & Delphinidae & 1 & 0,04 & 2 & 0,13 & & \\
\hline & Mamiferos & Monachus tropicalis & 1 & 0,04 & 8 & 0,51 & & \\
\hline & & Trichechus manatus & 3 & 0,13 & 2 & 0,13 & & \\
\hline & & Didelphis spp & 1 & 0,04 & & & 2 & 0,05 \\
\hline & 7 rimiï & Philander opossum & & & & & 1 & 0,02 \\
\hline & & $\begin{array}{l}\text { Philander opossum } \\
\text { o Marmosa spp }\end{array}$ & & & 1 & 0,06 & & \\
\hline & & Panthera onca & 2 & 0,08 & & & & \\
\hline & Felinos & Puma concolor & & & 1 & 0,06 & & \\
\hline & & $\begin{array}{l}\text { Mamifero } \\
\text { no identificado }\end{array}$ & 79 & 3,36 & 42 & 2,69 & 973 & 24,32 \\
\hline & & Callinectes sapidus & 3 & 0,13 & 1 & 0,06 & & \\
\hline$\approx$ & & $\begin{array}{l}\text { Cardisoma } \\
\text { guanhumi }\end{array}$ & 13 & 0,55 & & & & \\
\hline 峞 & 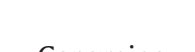 & Libinia emarginata & 1 & 0,04 & & & & \\
\hline$\stackrel{5}{5}$ & Cangrejos & Menippe mercenaria & 171 & 7,26 & 100 & 6,41 & & \\
\hline 는 & & Uca rapax & & & 1 & 0,06 & & \\
\hline & & $\begin{array}{l}\text { Braquiuro } \\
\text { no identificado }\end{array}$ & 3 & 0,13 & 15 & 0,96 & & \\
\hline & & No identificados & 61 & 2,59 & & & & \\
\hline
\end{tabular}


Al respecto, en Chichén Itzá se observa una clara preferencia hacia los animales tierra adentro. Especialmente el venado cola blanca constituye más de la mitad de la muestra (NISP $=2250$ de un total de 4002 especímenes). Mientras tanto, en Isla Cerritos el consumo de animales vertebrados fue más enfocado en especies costeras como tortugas marinas (NISP $=945$ de un total de 2354 especímenes), y peces (actinopterigios (NISP $=445$ ) y condrictios (NISP $=206$ ) de un total de 2354 especímenes), que en conjunto forman más de la mitad de la muestra faunística analizada.

Por otra parte, la comparación de la muestra de Isla Cerritos con la arqueofauna de Xcambó revela una similitud en los tipos y la frecuencia de los animales aprovechados; también en Xcambó se da una preferencia hacia el consumo de animales costeros como los peces (actinopterigios y condrictios, NISP $=597$ de un total de 1539 especímenes) y tortugas marinas (NISP $=357$ de un total de 1539 especímenes), los cuales constituyen más de la mitad de la muestra faunística. En ambos sitios se observa igualmente el consumo de animales terrestres, aunque en menor cantidad, de los cuales el más frecuente es el venado cola blanca.

Para esclarecer la relación entre el patrón de aprovechamiento del sitio de Isla Cerritos con los patrones de Chichén Itzá y Xcambó, se incluyó, como se ha estipulado arriba, un segundo nivel de análisis, más allá de la comparación del perfil faunístico. Este segundo nivel está enfocado en la identificación de los patrones de procesamiento, resultados de procesos tafonómicos antropogénicos y descritos arriba.

En la muestra zooarqueológica del sitio de Isla Cerritos, la preferencia hacia el consumo de animales marinos, como los peces (actinopterigios y condrictios), tortugas de mar, y crustáceos (cangrejos solamente) ha sido mencionada, habiendo existido también el consumo de animales terrestres, principalmente venados cola blanca. Del total de la muestra de Isla Cerritos (NISP $=2354$ ), sólo el 29\% presentó marcas antrópicas relacionadas a acciones de consumo alimentario por parte de los pobladores del sitio, predominando sobre todo el hervido como medio principal de procesamiento/preparación. Muy pocos de los restos presentaron más de una marca antrópica sobre su superficie. Los restos de peces actinopterigios con huellas de procesamiento (NISP $=115)$ muestran principalmente marcas de hervido $(95,7 \%)$, hallándose muy pocas que refieran un tratamiento con fuego directo (4,3\%), así como la ausencia de marcas de corte. Respecto a los peces condrictios (NISP $=127$ ), el 89,7\% de los especímenes presentaron marcas de hervido, de los cuales 3,9\% tenían marcas de corte igualmente; en menor frecuencia estuvieron presentes marcas de quemado $(5,5 \%)$ y de corte $(4,7 \%)$, algunas de éstas relacionadas a acciones de descarnamiento. Por otra parte, entre los restos de crustáceos (NISP $=114$ ) solamente se reconocieron dos tipos de marcas: el hervido $(71,9 \%)$ y el quemado $(28,1 \%)$.

Para los restos óseos de reptiles (NISP $=198$ ), las marcas antrópicas más frecuentes fueron las de hervido $(60,1 \%)$ y corte $(39,9 \%)$; sin embargo, hay que 
considerar que la frecuencia de éstas fue muy baja en relación al conteo de especímenes para dicha clase taxonómica dentro del total de la muestra. La mayor cantidad de estos restos se atribuye a tortugas (NISP $=151)$ marinas y terrestres (aunque esta última en menor grado), entre las cuales la presencia de marcas de preparación alimentaria estuvo orientada a dos procesos de tratamiento: 1) las marcas de corte (37\%), que incluían las tareas de descarnamiento y ruptura del caparazón para la obtención de carne, y 2) las marcas de hervido (49\%) y quemado (14\%), que podrían estar implicando el siguiente proceso en la preparación de los alimentos, la cocción de los ingredientes, en este caso la carne. Otra especie de reptil presente en la muestra fue la iguana rayada, cuyos restos óseos presentaron únicamente huellas de hervido (el 22,2\% del total de esta especie).

Respecto a los restos óseos de mamíferos (NISP $=98$ ), principalmente venados cola blanca $(62,2 \%)$ (figura 3), las huellas observables reflejan un patrón muy diferente a los que presentan las otras clases taxonómicas, ya que en el $69 \%$ de estos restos se observa la presencia de dos o tres marcas antrópicas en un mismo espécimen (p. ej. hervido y corte; hervido y fractura; o hervido, fractura y corte). Esto puede deberse principalmente a la factibilidad de identificar estas marcas en los restos óseos de los mamíferos, y a la posibilidad que existe de obtener de esta clase taxonómica un recurso alimenticio muy importante, la médula ósea, lo que incrementa la presencia de marcas como la fractura en fresco. Las marcas antrópicas se presentan en su gran mayoría en huesos largos, como fémures, húmeros, metapodios, tibias y radio-ulnas. La principal marca de procesamiento que se observó en los restos óseos es el hervido $(57,1 \%)$, seguido por las marcas de fractura (54\%), las huellas de corte $(26,5 \%)$ y, finalmente, las marcas de quemado $(11,2 \%)$. Por último, puede mencionarse que las marcas presentes en los restos óseos de aves (NISP $=9$ ) se resumen en dos grupos, marcas de hervido $(22,2 \%)$ y marcas de quemado $(77,8 \%)$.

Resumiendo el estudio de las marcas antropogénicas que se hallaron en los restos de fauna de Isla Cerritos puede constatarse que la principal marca de procesamiento fue el hervido, mientras que las marcas de corte se presentaron principalmente en restos óseos del caparazón de reptiles y en huesos largos (metapodios y fémures, especialmente) dentro del grupo de los mamíferos, considerando en ambos casos que dichas marcas se relacionan con los procedimientos de obtención de carne (descarnamiento, desmembramiento, desarticulación y despellejamiento). Las marcas de fractura, poco representadas en otras clases taxonómicas, se presentan en los restos de huesos largos de los mamíferos, y esta incidencia puede deberse al intento de obtener la médula ósea de dichos animales.

En cuanto al cotejo de datos entre las muestras zooarqueológicas de Isla Cerritos, Xcambó y Chichén Itzá, debe notarse que no todos los taxones pudieron ser comparados, debido a la ausencia de algunos de ellos en cierta(s) muestra(s), así como a la baja frecuencia de especímenes con huellas antrópicas de unos 
taxones. En ciertos casos, aun con un elevado conteo de especímenes para cierta especie, muy pocos presentaron marcas antrópicas, por lo que estos datos no pudieron ser considerados como un referente para entender las técnicas de procesamiento empleadas para el consumo de una determinada especie animal.

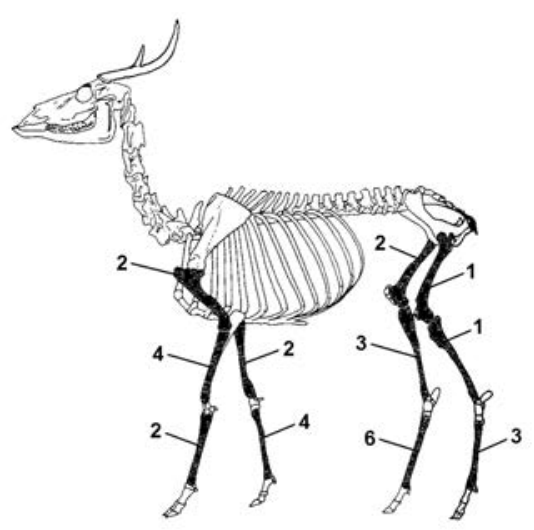

Marcas de fractura

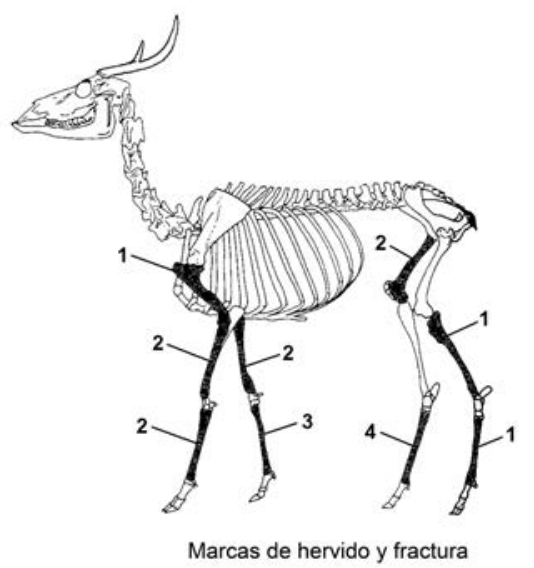

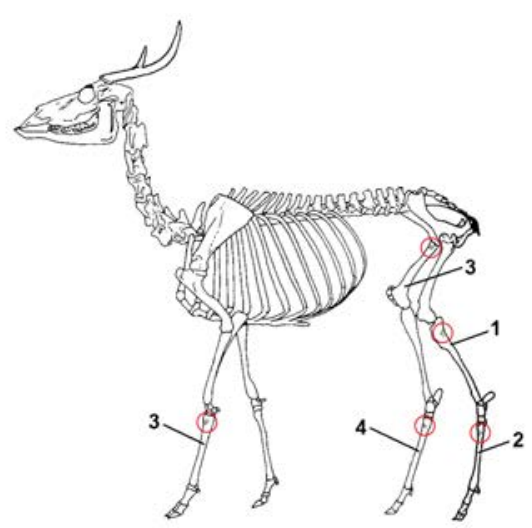

Marcas de corte

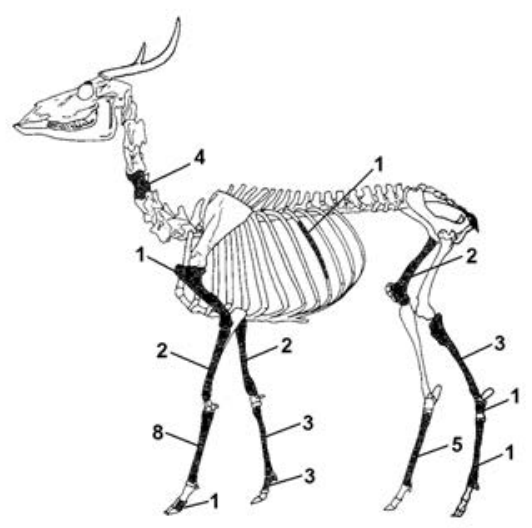

Marcas de hervido

FIgURA 3. Marcas antrópicas en restos óseos de venado cola blanca (Odocoileus virginianus) en el sitio de Isla Cerritos (tomada de Götz, 2007b, y modificada por Herrera Flores).

La única especie animal, entre las tres muestras, que pudo ser comparada con base en la frecuencia de especímenes y de marcas antrópicas fue el venado cola blanca (Odocoileus virginianus). Respecto a los restos óseos de esta especie en el sitio de Chichén Itzá, las marcas antrópicas identificadas (figura 4) expresan un patrón muy similar al que se puede observar en Isla Cerritos, es decir, una 
gran cantidad y variedad de marcas en los huesos de este rumiante, así como la combinación de éstas, siendo la más común la presencia de marcas de hervido y fractura en un mismo espécimen.

En Chichén Itzá, de los 2250 huesos y fragmentos óseos de esta especie (60\% de toda la muestra) que presentaron marcas antrópicas destacan los fragmentos procedentes de las piernas delanteras y traseras, especialmente del húmero, fémur, radio-ulna y tibia. Estos fragmentos muestran una mayor frecuencia de alteraciones en forma de huellas de haber sido rotos en estado fresco (77\%) y de haber sido hervidos (59\%) (Götz, 2007b). La presencia de patrones comunes en ambos sitios como marcas de hervido y fractura en los restos óseos, especialmente en los huesos largos de las extremidades traseras y delanteras, nos permite apreciar que las técnicas aplicadas en el procesamiento del venado cola blanca fueron similares, orientadas hacia la cocción mediante el hervido y hacia la obtención de la médula ósea fracturando el hueso.

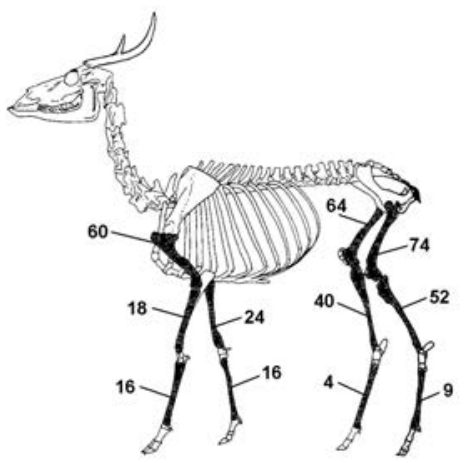

Marcas de fractura

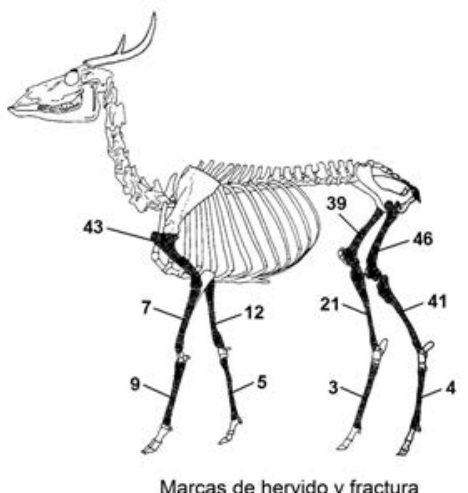

Marcas de hervido y fractura

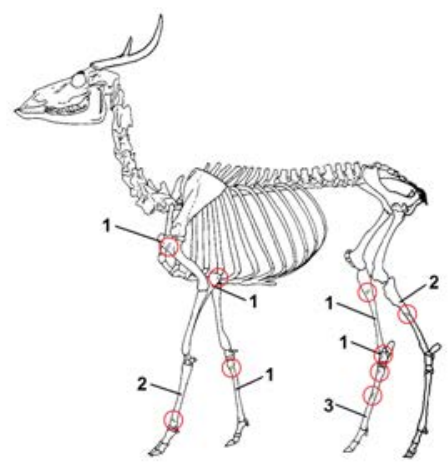

Marcas de corte

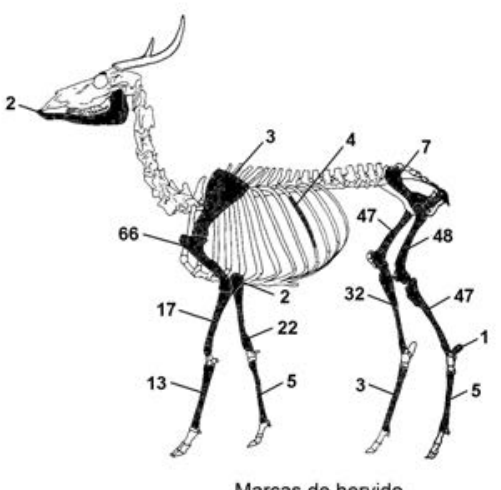

Marcas de hervido

FIGURA 4. Marcas antrópicas en restos óseos de venado cola blanca (Odocoileus virginianus) en el sitio de Chichén Itzá (tomada de Götz, 2007b, y modificada por Herrera Flores). 
En cuanto a la muestra zooarqueológica del sitio de Xcambó, las marcas más comunes en los restos óseos de venado cola blanca (figura 5) indican que sus partes fueron hervidas $(77 \%$ ) y fracturadas $(27 \%)$, habiendo marcas aisladas o combinadas en fémures, tibias, húmeros, radio-ulnas y metapodios. En pocos especímenes se presentaron huellas de desarticulación, despellejamiento y descarnamiento. Esto muestra que el modo de procesamiento del venado cola blanca en Xcambó fue muy similar a los que se observaron en los sitios de Chichén Itzá e Isla Cerritos, ya que las partes anatómicas procesadas y las huellas presentes en ellas son muy equivalentes.

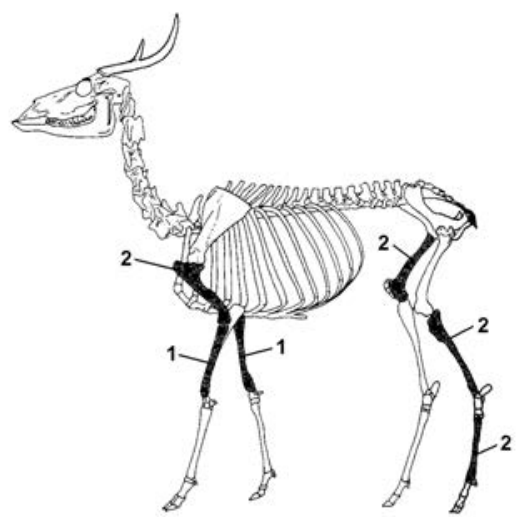

Marcas de fractura

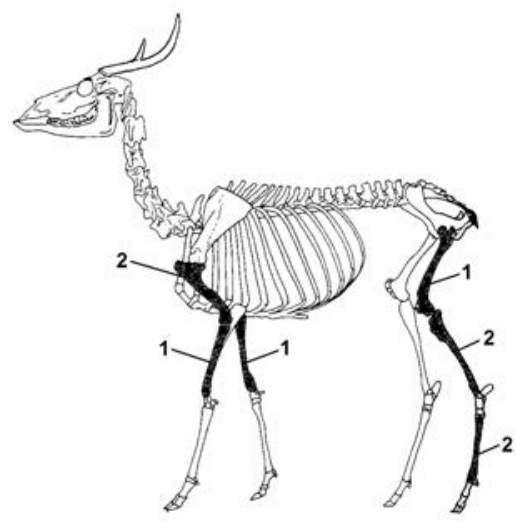

Marcas de hervido y fractura

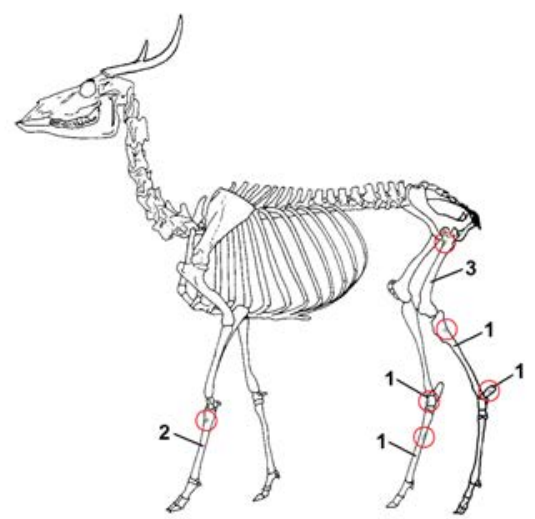

Marcas de corte

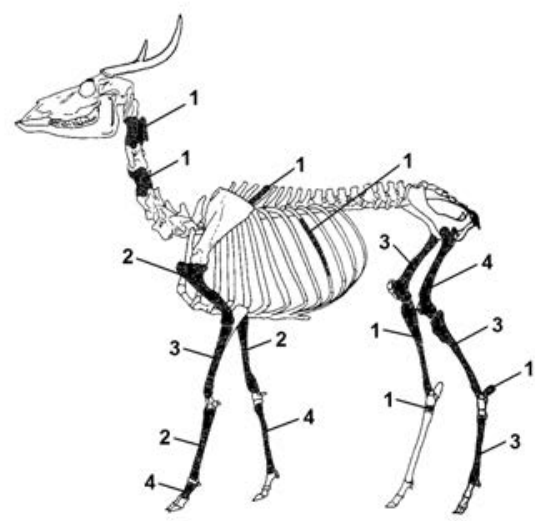

Marcas de hervido

Figura 5. Marcas antrópicas en restos óseos de venado cola blanca (Odocoileus virginianus) en el sitio de Xcambó (tomada de Götz, 2007b, y modificada por Herrera Flores). 
Estos datos parecen reflejar un modo general de procesar los alimentos, en este caso una práctica generalizada en el tratamiento del venado cola blanca para la preparación alimentaria. Este resultado corresponde con los datos obtenidos en un estudio zooarqueológico realizado en tres sitios arqueológicos de tierra adentro del norte de la península yucateca (Chichén Itzá, Sihó y Dzibilchaltún) (Götz, 2010), que intentó relacionar las marcas antropogénicas encontradas en los especímenes esqueléticos a modos de alimentación cárnica tradicional ligados a la cultura maya de las Tierras Bajas mayas del norte, a través del cotejo de las marcas tafonómicas y perfiles taxonómicos en las tres muestras arqueofaunísticas.

El objetivo de este estudio fue reconstruir cómo y cuál animal se comió y si algunas maneras de consumo observadas en la actualidad tuviesen raíces en el pasado. Varios animales, como la paca, el pizote, el pecarí de collar, el pecarí de labios blancos, el venado cola blanca, el venado temazate, el pavo de monte y la iguana rayada, se consumen en la región desde tiempos prehispánicos, presentándose también en la dieta de los habitantes coloniales y modernos (Götz, 2010: 98).

El análisis de las marcas tafonómicas relacionadas a actividades de procesamiento indica notablemente la gran cantidad de huesos, predominantemente de venado cola blanca, que presentan huellas de hervido y de fractura en fresco, mientras hay pocas huellas de corte y de fuego directo. Estos rasgos podrían interpretarse en el sentido de la existencia en el pasado de un proceso para guisar carnes que es actualmente utilizado de manera tradicional en contextos rurales: el horno bajo tierra o púib (Götz, 2010: 102). Los hornos subterráneos consisten en cavidades excavadas en la tierra, cuyas dimensiones dependen de la cantidad de alimento que va a ser cocinada, y en las que se coloca una base de piedras cubierta con madera que luego se enciende para poder calentarlas. Una vez que la madera se haya consumido, el animal completo o porciones de este son colocados sobre la superficie de las rocas dentro de un recipiente, o sobre una base de hojas, para posteriormente ser cubierto con hojas y finalmente con tierra (Salazar et al., 2012; Götz, 2010).

Al preparar partes de animales en estos hornos subterráneos, se alcanza un cocimiento de la carne, mientras que los huesos presentan huellas de hervido por la afectación de las altas temperaturas, lo que podría corresponder con los rasgos tafonómicos encontrados en el registro arqueológico; además, cuando se cuece un animal en el píib se hace de manera casi completa, y un despiece posterior por medio de implementos cortantes es prácticamente innecesario, ya que las articulaciones y la masa muscular han sido suavizadas por medio de la cocción (Götz, 2010). Aunque la presencia de huesos hervidos en las muestras arqueofaunísticas no comprueba en sí el uso de este método de cocción, puede argumentarse que la baja frecuencia de marcas de despiece y descarnamiento, aunada a dichas marcas de calor, puede entenderse como indicio de que el púib se practicaba desde tiempos prehispánicos. Este argumento puede fundamentarse 
con los datos obtenidos en un estudio etnográfico (Salazar et al., 2012) realizado en la comunidad de Xocén, en Yucatán, sobre el horno subterráneo o píib, en donde los resultados reflejan una predominancia en el uso de plantas nativas para la elaboración de los hornos subterráneos, así como un mayor consumo de especies animales locales cocinadas en ellos; por lo que, tomando en consideración esta predominancia de elementos locales, es probable que los hornos subterráneos fueran también usados en época prehispánica, ya que se considera la existencia de una continuidad en el uso de ciertos elementos que responden al con qué y para qué se construye.

\section{Discusión: La preparación de los alimentos como un rasgo cultural de identidad entre los mayas prehispánicos de la Península de Yucatán}

La similitud que se manifiesta en el tratamiento del venado cola blanca en los dos estudios (Götz, 2010; Herrera Flores, 2011) aquí tratados parece responder a un patrón general en el modo de aprovechamiento de la fauna regional del norte de las Tierras Bajas mayas. Considerando además los datos modernos y arqueofaunísticos al respecto del uso del píib y de la ocurrencia de huesos hervidos con pocas marcas de despiece, podemos suponer la posibilidad del desarrollo y mantenimiento de modos de procesamiento generalizados, que permitieron la cocción de los animales, en forma entera o en porciones anatómicas grandes, por medio del hervido o en hornos subterráneos (Götz, 2010: 108).

Las características propias de las muestras comparadas, como el aprovechamiento de especies que habitan en ambientes cercanos a los asentamientos y la similitud que se aprecia en las técnicas de procesamiento del venado cola blanca, sugieren un proceso de adaptación y optimización de los recursos que se presentan en cada ambiente ecológico, así como una continuidad en los patrones de aprovechamiento de los recursos. Sin embargo, la reconstrucción de los modos de procesamiento de animales que permita establecer una diferenciación culinaria entre los contextos arqueológicos cotejados, con base en los datos que revelan los primeros procesos en la preparación de los alimentos como el despellejamiento, el despiece, el descarnado y la cocción, no es tan clara al respecto, sobre todo si consideramos las limitantes en el análisis tafonómico de las marcas observadas en la superficie de los huesos, que en muchos casos no logran conservarse o se presentan en forma aislada, por lo que la conformación de patrones específicos puede ser muy complicada.

Esto nos permite plantear el hecho de que quizá la diferencia (o incluso una reafirmación de la semejanza) en el patrón culinario de preparación de los alimentos entre los sitios analizados pudiera estar más relacionada a las formas en que los ingredientes (en este caso de origen animal) pudieran ser mezclados con otros (de origen vegetal o animal igualmente) para la elaboración de diferentes platillos - desde que se han podido encontrar residuos químicos en vasijas que 
muestran el antiguo contenido (Pecci y Cau Ontiveros, 2010), queda por estudiarse si pudieran hallarse también restos de preparación en huesos de animales.

Sin embargo, hasta el momento este tipo de interpretación difícilmente podrá realizarse, ya que dentro de una muestra faunística es posible reconocer los perfiles taxonómicos y tener un acercamiento a los modos de preparación de los alimentos, pero no cómo los diferentes componentes presentes en la muestra se pudieron haber combinado para la conformación de un determinado platillo o guisado en el pasado.

Respecto al estudio realizado en Isla Cerritos, y si el aprovechamiento de animales vertebrados en el sitio refleja un patrón particular influido por tendencias alimentarias del sitio de Chichén Itzá podemos mencionar lo siguiente: evidentemente, la estrecha relación comercial entre los sitios de Isla Cerritos y Chichén Itzá produjo un cambio en el modo de vida de los habitantes del asentamiento costero, y llevó al desarrollo de este sitio como uno de los principales puertos de intercambio durante el periodo Clásico Terminal. Asimismo, esta relación introdujo en Isla Cerritos nuevos elementos culturales relacionados con el surgimiento de una ideología panmesoamericana en Chichén Itzá, misma que pudo haber influido en el modo de alimentación en ambos lugares si tomamos en consideración el factor cultural e ideológico en la selección y preparación de los alimentos; sin embargo, en Isla Cerritos no se puede reconocer un patrón de aprovechamiento particular que lo distinga, en relación a otros sitios costeros, y que pudiera hablar de un modo de alimentación singular ligado a estos nuevos rasgos culturales. Únicamente se puede apreciar un fuerte lazo con el medio ambiente, reflejado en una explotación oportunista de los recursos marinos, permitiéndoles el aprovechamiento de especies animales únicas del mar.

Con base en la información de los estudios aquí tratados podemos argumentar que si bien no es posible determinar rasgos culinarios particulares que reflejaran una identidad social entre diferentes grupos o asentamientos precolombinos, se han podido reconocer ciertas pautas o patrones de la alimentación cárnica de los mayas prehispánicos que pudieran haber constituido una permanencia cultural a lo largo del tiempo hasta nuestros días. En tal caso, existe la posibilidad de que el uso del píib se remonte a tiempos prehispánicos y represente una continuidad cultural que ayude a identificar una expresión de identidad (Götz, 2010), sobre todo si consideramos que el uso y construcción de los hornos subterráneos pueden promover la creación de vínculos y funciones comunitarias como un elemento de identidad de una comunidad (Salazar et al., 2012).

\section{Consideraciones finales}

Esta investigación se propuso estudiar el modo de alimentación de los mayas prehispánicos por medio del análisis de muestras arqueofaunísticas de sitios costeros y de tierra de adentro de las Tierras Bajas mayas. Esta temática se abordó 
a partir de la inferencia de rasgos de identidad a través de los restos óseos de animales producto de actividades de consumo alimentario, en otras palabras, el estudio de la identidad por medio del análisis de la alimentación de un determinado grupo.

Los resultados obtenidos de los análisis de muestras arqueofaunísticas de sitios prehispánicos de Yucatán (Isla Cerritos, Chichén Itzá, Xcambó), fechadas para los periodos Clásico Tardío y Terminal, permitieron apreciar un aprovechamiento faunístico que se enfocaba en la caza de animales que habitaban en áreas aledañas a los asentamientos. Asimismo, la estrecha relación entre Isla Cerritos y Chichén Itzá, así como el desarrollo de nuevos rasgos culturales en ambos lugares, parecen no estar relacionados con un patrón de aprovechamiento particular del ambiente, más bien puede argumentarse la presencia de patrones que responden a un conocimiento sobre explotación de especies animales de acuerdo al ambiente en el que se encuentren, en otras palabras, una adaptación ambiental.

Por otra parte, la determinación de los modos de procesamiento de los animales a través del estudio de las marcas antrópicas, específicamente aquellas presentes en los restos óseos de venados cola blanca, nos permitió reconocer el empleo de técnicas generalizadas para la región. Asimismo, la posibilidad de la trascendencia temporal y continuidad en el uso de la técnica de cocción a través de los hornos subterráneos o píib parece tener una correspondencia que se puede observar en las marcas tafonómicas de la superficie de los restos esqueléticos arqueológicos y en aquellas que se han identificado en las muestras modernas de conjuntos faunísticos (Götz, 2010).

Por tanto, puede sugerirse que la identidad social, al referirse a la autoadscripción de un individuo como parte de un grupo por compartir ciertas características, como en este caso específico la alimentación, parece estar presente en al menos algunos de los patrones de alimentación cárnica de la cultura maya. Al identificarse maneras de consumo que tienen raíces prehispánicas, hablamos entonces de la posibilidad de hacer visible una forma de identidad social, expresada en la manera tradicional y típica de aprovechar recursos y procesar alimentos (Götz, 2010). Esto también nos habla de la presencia de patrones culturales que han persistido al devenir del tiempo histórico, aunque con sus respectivos ajustes y resignificaciones, que dan cuenta de la importancia que algunos elementos culturales tienen para los mayas yucatecos contemporáneos (Götz, 2010). 


\section{BIBLIOGRAFÍA}

Andrews, Anthony P. y Tomás Gallareta Negrón

1986 "The Isla Cerritos Archaeological Project Yucatán, México”, Mexicon, VIII (3): 44-48. Markt Schwaben: Verlag Anton Sauwein.

Andrews, Anthony P., Tomás Gallareta Negrón, Fernando Robles Castellanos y Rafael Cobos Palma

1984 Proyecto arqueológico Isla Cerritos. Reporte de la temporada de campo de 1984. Reporte para el Consejo Nacional de Arqueología, Instituto Nacional de Antropología e Historia. México, D. F.

Andrews, Anthony P., Tomás Gallareta Negrón, Fernando Robles Castellanos, Rafael Cobos Palma y Pura Cervera R.

1986 Proyecto arqueológico Isla Cerritos. Reporte de la temporada de campo de 1985. Reporte para el Consejo Nacional de Arqueología, Instituto Nacional de Antropología e Historia. México, D.F.

1988 "Isla Cerritos: An Itzá Trading Port on the North Coast of Yucatán, México", National Geographic Research, 4 (2): 196-207. Washington, D.C.: National Geographic Society.

Boscato, Paolo

2001 "Arqueozoología”, Diccionario de arqueología, R. Francovich y D. Manacorda (eds.). Barcelona: Editorial Crítica, pp. 36-41.

Braswell, Geoffrey

1997 “El intercambio prehispánico en Yucatán, México”, X Simposio de Investigaciones Arqueológicas en Guatemala, J. P. Laporte y H. Escobedo (eds.). Guatemala: Museo Nacional de Arqueología y Etnología, pp. 595-606.

Cárdenas Cervantes, José Miguel

2012 "El uso de las tortugas marinas (Caretta caretta, Chelonia mydas y Eretmochelys imbricata) en la sociedad maya prehispánica de Xcambó”, tesis de licenciatura en Arqueología. Yucatán: Universidad Autónoma de Yucatán.

Cobos, Rafael, Lilia Fernández Souza, Rodolfo Canto Carrillo, Vera Tiesler Blos, Andrea Cucina, Socorro del Pilar Jiménez Álvarez, Christopher Götz, Guillermo de Anda Alaniz y Nancy Peniche May

2007 Proyecto arqueológico Isla Cerritos. Estudio de una comunidad maya costera del Clásico Terminal. Informe de la temporada de campo 2006. Reporte para el Consejo Nacional de Arqueología, Instituto Nacional de Antropología e Historia. Yucatán: Universidad Autónoma de Yucatán.

Cobos, Rafael, Rodolfo Canto Carrillo, Dylan J. Clark, Socorro Jiménez Álvarez, Cecilia Soldevila Illingworth, Christopher Götz, Mauricio Germon Roche, Guillermo de Anda Alanís y Geoffrey Braswell

2010 Proyecto arqueológico Isla Cerritos. Estudio de una comunidad maya costera del Clásico Terminal. Informe de la temporada de campo 2007. Reporte para el Con- 
sejo Nacional de Arqueología, Instituto Nacional de Antropología e Historia. Yucatán: Universidad Autónoma de Yucatán.

Contreras, Jesús

2002 "Introducción", Alimentación y cultura. Necesidades, gustos y costumbres, J. Contreras (comp.). México: Editorial Alfaomega, pp. 9-24.

Counihan, Carole M.

1999 The Anthropology of Food and Body. Gender, Meaning, and Power. New York: Routledge.

Douglas, Mary

2002 "Las estructuras de lo culinario", Alimentación y cultura. Necesidades, gustos y costumbres, J. Contreras (comp.). México: Editorial Alfaomega, pp. 171-198.

Ellen, Roy F.

2001 "La geometría cognitiva de la naturaleza. Un enfoque contextual”, Naturaleza y sociedad. Perspectivas antropológicas, P. Descola y G. Pálsson (coords.). México: Siglo XXI Editores, pp.124-146.

Emery, Kitty F.

2002 "Evidencia temprana de explotación animal en el altiplano de Guatemala", Utz’ib, 3 (2): 1-16. Guatemala: Asociación Tikal.

Gallareta Negrón, Tomás y Anthony P. Andrews

1988 "El proyecto arqueológico Isla Cerritos Yucatán, México", Boletín de la Escuela de Ciencias Antropológicas de la Universidad de Yucatán, 5 (89): 3-16. Yucatán: Universidad Autónoma de Yucatán.

Gallareta Negrón, Tomás, Anthony P. Andrews, Rafael Cobos Palma y Pura Cervera Rivero 1989 "Isla Cerritos: Un puerto maya prehispánico de la costa norte de Yucatán, México”, Memorias del Segundo Coloquio Internacional de Mayistas, México: Universidad Nacional Autónoma de México, pp. 311-332.

Gates St-Pierre, Christian

2006 "Faunal Remains as Markers of Ethnicity: a Case Study from the St. Lawrence Estuary, Quebec, Canadá”, ponencia presentada en la X Conferencia del Consejo Internacional de Arqueozoología (ICAZ). México, D.F.

Götz, Christopher M.

2005 "El consumo de vertebrados en tres grupos habitacionales de Sihó, Yucatán”, XVIII Simposio de Investigaciones Arqueológicas en Guatemala, J. P. Laporte, B. Arroyo, H. Escobedo y H. Mejía (eds.). Guatemala: Museo Nacional de Arqueología y Etnología, pp. 809-825.

2007a "Manjares del pasado: contraste del aprovechamiento faunístico entre sitios prehispánicos costeros y de tierra adentro de las tierras bajas del norte", Memorias del XXI Simposio de Investigaciones Arqueológicas en Guatemala, J. P. Laporte y B. Arroyo (eds.). Guatemala: Museo Nacional de Arqueología y Etnología, pp. 781-798. 
2007b "El aprovechamiento de animales vertebrados en Chichén Itzá, Yucatán. Uso alimenticio y ritual”, Chichén Itzá. Nuevas interpretaciones históricas, A. Voss y A. Koechert (eds.). Hannover: Verlag für Ethnologie (Colección Americana, No. 6), pp. 51-74.

2008a "Coastal and Inland Patterns of Faunal Exploitation in the Prehispanic Northern Maya Lowlands", Quaternary International, 191: 154-169, K. F. Emery, C. M. Götz, M. E. Hill, JR. y J. Arroyo Cabrales (eds.). Dorchester: INQUA/ Elsevier.

2008b Die Verwendung von Wirbeltieren durch die Maya des nördlichen Tieflandes während der Klassik und Postklassik (600-1500 n.Chr.). Rahden, Westfahlen: Verlag Marie Leidorf (Serie Internationale Archäologie, No. 106).

2010 "Una mirada zooarqueológica a los modos alimenticios de los mayas de las tierras bajas del norte”, Identidades y cultura material en la región maya, $\mathrm{H}$. Hernández Álvarez y M. N. Pool Cab (eds.). Yucatán: Universidad Autónoma de Yucatán, pp. 89-109.

2012 "Caza y pesca prehispánica en la costa norte peninsular yucateca”, Ancient Mesoamerica, 23 (2): 421-439. Cambridge: Cambridge University Press.

Götz, Christopher M. y Thelam Noemí Sierra Sosa

2011 "La arqueofauna de Xcambó, Yucatán, México", Antípoda. Revista de Antropología y Arqueología, 13: 119-145. Bogotá: Universidad de los Andes.

Hernando, Almudena

2002 Arqueología de la identidad. Madrid: Ediciones Akal.

Herrera Flores, David Alejandro

2011 "Aspectos culinarios relacionados a la identidad de los antiguos habitantes de Isla Cerritos, Yucatán: Un estudio zooarqueológico”, tesis de licenciatura en Arqueología. Yucatán: Universidad Autónoma de Yucatán.

Jiménez Álvarez, Socorro del Pilar

2002 "La cronología cerámica del puerto maya de Xcambó, costa norte de Yucatán: complejo cerámico Xcambó y complejo cerámico Cayalac”, tesis de licenciatura en Arqueología. Yucatán: Universidad Autónoma de Yucatán.

Jiménez Cano, Nayeli Guadalupe

2009 "Ecología y subsistencia en la costa peninsular yucateca (250 d.C.-1550 d.C): un acercamiento paleoecológico a través de la arqueofauna costera”, tesis de licenciatura en Arqueología. Yucatán: Universidad Autónoma de Yucatán.

Kowalski, Jeff Karl y Cynthia Kristian-Graham (eds.)

2007 Twin tollans: Chichén Itzá, Tula, and the Epiclassic to Early Postclassic Mesoamerican world. Washington: Harvard University Press.

Lyman, R. Lee

2001 Vertebrate Taphonomy. Cambridge: Cambridge University Press (Cambridge Manuals in Archaeology). 
Márquez-Morfín, Lourdes

1991 "La dieta maya prehispánica en la costa yucateca", Estudios de Cultura Maya 18: 359-394. México: Universidad Nacional Autónoma de México, Instituto de Investigaciones Filológicas, Centro de Estudios Mayas.

Messer, Ellen

2002 "Perspectivas antropológicas sobre la dieta", Alimentación y cultura. Necesidades, gustos y costumbres, J. Contreras (comp.). México: Editorial Alfaomega, pp. 27-81.

Nicholson, Rebecca A.

1998 "Bone degradation in a compost heap", Journal of Archaeological Science, 25 (5): 393-403. Dorchester: Elsevier.

Pecci, A. y M. Á. Cau Ontiveros

2010 "Análisis de residuos orgánicos en ánforas: el problema de la resina y el aceite", Estudios sobre el monte Testaccio (Roma) V, J. Ma. Blázquez Martínez y J. Remesal Rodríguez (eds.). Barcelona: CEIPAC-Universitat de Barcelona (Colección Instrumenta, No. 35), pp. 593-600.

Peláez Casabianca, Manuel

1997 "Consideraciones teóricas", Presencia de la antropología en los estudios sobre alimentación. México: Universidad Nacional Autónoma de México, Instituto de Investigaciones Antropológicas (Cuadernos de Trabajo), pp. 13-19.

Pérez Ruiz, Maya Lorena

1992 "La identidad como objeto de estudio", I Seminario sobre identidad, L. I. Méndez y Mercado (comp.). México: Universidad Nacional Autónoma de México, Instituto de Investigaciones Antropológicas, pp. 61-69.

Reitz, Elizabeth J. y Elizabeth S. Wing

2008 Zooarchaeology, 2a ed. New York: Cambridge University Press (Cambridge Manuals in Archaeology).

Rozin, Paul

2002 "Perspectivas psicobiológicas sobre las preferencias y aversiones alimentarias", Alimentación y cultura. Necesidades, gustos y costumbres, J. Contreras (comp.). México: Editorial Alfaomega, pp. 85-109.

Salazar, Carmen, Daniel Zizumbo-Villarreal, Stephen B. Brush y Patricia Colunga-García Marín 2012 "Earth Ovens (Píib) in the Maya Lowlands: Ethnobotanical Data Supporting Early Use”, Economic Botany, 66 (3): 285-297. New York: The New York Botanical Garden Press-Springer.

Shack, Dorothy N.

2002 "El gusto del catador: determinantes sociales y culturales de las preferencias alimentarias", Alimentación y cultura. Necesidades, gustos y costumbres, J. Contreras (comp.). México: Editorial Alfaomega, pp. 111-125. 
Tappan Merino, José Eduardo

1992 "Cultura e identidad", I Seminario sobre identidad, L. I. Méndez y Mercado (comp.). México: Universidad Nacional Autónoma de México, Instituto de Investigaciones Antropológicas, pp. 70-90.

Vigliani, Silvina

2006 "Arqueología de la identidad en el estudio de la diversidad social", Perspectivas de la investigación arqueológica II. Homenaje a Gustavo Vargas, C. Corona, P. Fournier y A. Villalobos (coords.). México: Consejo Nacional para la Cultura y las Artes / Instituto Nacional de Antropología e Historia / Escuela Nacional de Antropología e Historia, pp. 253-267.

Wing, Elizabeth S.

1981 "A comparison of olmec and maya foodways", The Olmec and their Neighbors, E. Benson (ed.). Washington, D.C.: Dumbarton Oaks, pp. 21-28. 